\title{
Selenium geochemistry at the sediment-water interface of a Subarctic Canadian Lake impacted by mining activities
}

\author{
DENALI MOKRIS ${ }^{1}$, STEPHAN R. HLOHOWSKY ${ }^{1}$, \\ JENNIFER GALLOWAY ${ }^{2}$, OMID HAERI ARDAKANI ${ }^{2}$ AND \\ ANTHONY CHAPPAZ ${ }^{1}$ \\ ${ }^{1}$ STARLAB- Central Michigan University \\ ${ }^{2}$ Geological Survey of Canada \\ Presenting Author: mokri1d@cmich.edu
}

At low concentrations $(<5 \mathrm{ppb})$, selenium $(\mathrm{Se})$, a redox sensitive trace element, is a bioessential micro nutrient but above that threshold, it can be toxic to all life forms. In addition, Se speciation is known to play a significant role in controlling its ecotoxicity and reactivity in aquatic systems. Previous studies focusing on mining impacts on Se geochemistry are rather sparse. Identifying geochemical reactions involving Se at the sediment-water interface (SWI), as well as assessing how mining activities may have altered natural Se fluxes reaching the SWI in freshwater boreal systems is vital if we hope to examine how this trace element builds up in the environment and whether it potentially poses risks to wildlife and human health. In this study we examine: 1) which geochemical controls are involved in Se burial at the SWI and 2) how gold mining activities may have impacted the flux of Se reaching the SWI over the last century.

Handle Lake is located $\sim 1.5 \mathrm{~km}$ from the former Giant Mine, a gold mine operating in the Northwest Territories, Canada for over fifty years, which stopped all operations in 2004 . A $27 \mathrm{~cm}$ sediment core from the lake was collected in 2018 with porewater samples. Sediment samples were totally digested using a combination of ultra-pure acids at the STARLAB. Major and minor element concentrations were determined for all samples with inductively coupled plasma mass spectrometry. The sediment core was dated by measuring the activities of ${ }^{210} \mathrm{~Pb}$ and ${ }^{137} \mathrm{Cs}$ using gamma spectrometry. Our preliminary results shed new light on the geochemical controls involved during Se burial and indicate that Giant Mine operations may have changed the natural Se flux reaching the SWI of Handle Lake. Future steps will determine precisely how much Se was released in the environment around Yellowknife and inform the local communities about associated risks and needed mitigation plans. 